\title{
A NEW SPECIES OF GALUMNA (ACARI, ORIBATIDA, GALUMNIDAE) FROM ETHIOPIA
}

\author{
Sergey G. Ermilov ${ }^{*}$ and Leonid B. Rybalov ${ }^{2}$
}

\author{
${ }^{1} \mathrm{X}-\mathrm{BIO}$ Institute, Tyumen State University, Tyumen, Russia \\ ${ }^{2}$ A.N. Severtsov Institute of Ecology and Evolution, Moscow, Russia \\ *corresponding author; e-mail: ermilovacari@yandex.ru
}

\begin{abstract}
A new oribatid mite species of the genus Galumna (Oribatida, Galumnidae) is described from Ethiopia, based on the material collected from litter and fallen leaves on the Sanetti Plateau, Bale Mountains. Galumna (Galumna) paracapensis Ermilov sp.n. differs from Galumna (Galumna) capensis Engelbrecht, 1969 in larger body size, strongly elongate postanal porose area, long longitudinal parts of porose areas $A a$ and the presence of sculpturing on prodorsum and pteromorphs.
\end{abstract}

KEY WORDS: Galumnid mites, systematics, morphology, Ethiopian region.

DOI: 10.21684/0132-8077-2020-28-1-23-28

\section{INTRODUCTION}

This work is a part of our continuing study of oribatid mites (Acari, Oribatida) of Ethiopia (e.g., Ermilov and Rybalov 2018, 2019; Ermilov 2019). It is based on oribatid mite material collected on the Sanetti Plateau of the Bale Mountains in the course of the Russian-Ethiopian expedition in 2014. During taxonomic identification, we found one new species belonging to the genus Galumna Heyden, 1826 (nominative subgenus) of the family Galumnidae. The primary goal of the paper is to describe and illustrate this new species.

At present, the Ethiopian oribatid mite fauna is fairly well studied, and six species of Galumna (Galumna) have been recorded: G.(G.) anuakensis Ermilov, 2019; G.(G.) flabellifera Hammer, 1958; G.(G.) gambelaensis Ermilov, 2019; G.(G.) incisa Mahunka, 1982; G.(G.) lanceosensilla Ermilov, Sidorchuk and Rybalov, 2011; G.(G.) nuda Engelbrecht, 1972 (e.g., Mahunka 1982; Ermilov et al. 2012; Ermilov 2016; Ermilov and Rybalov 2019).

\section{MATERIALS AND METHODS}

Litter and fallen leaves were collected using a stainless-steel frame $(50 \times 50 \mathrm{~cm})$ with a sieve (mesh size $2 \times 2 \mathrm{~cm}$ ). Mites were extracted into $75 \%$ ethanol using Berlese's funnels with electric lamps in laboratory conditions.

The specimens were mounted in lactic acid on temporary cavity slides for measurement and illustration. The body length was measured in lateral view, from the tip of the rostrum to the posterior edge of the notogaster (behind pteromorphs). The notogastral width refers to the maximum width of the notogaster in dorsal view. All body measurements are presented in micrometers $(\mu \mathrm{m})$. The formulas for leg setation are given in parentheses according to the sequence trochanter-femur-genutibia-tarsus (famulus included). The formulas for leg solenidia are given in square brackets according to the sequence genu-tibia-tarsus.

The drawings were made with a camera lucida using a Leica transmission light microscope "Leica DM 2500". The microscope images were obtained with an AxioCam ICc3 camera using a Carl Zeiss transmission light microscope "Axio Lab.A1".

Morphological terminology used in this paper follows that of F. Grandjean (see Ermilov and Klimov 2017 for review and application).

The following abbreviations are used: $L-$ lamellar line; $S$-sublamellar line; $N$-prodorsal leg niche; $E, T$-lateral ridges of prodorsum; ro, le, in, $b s$-rostral, lamellar, interlamellar and bothridial setae, respectively; $A d$ - sejugal porose area; $D$ dorsophragma; $P$ - pleurophragma; $c, l a, l m, l p, h$, $p$-notogastral setal alveoli; $A a, A l, A 2, A 3$-notogastral porose areas; $m p$-median pore; $i a, i m$, $i p$, ih, ips-notogastral lyrifissures; gla-opisthonotal gland opening; $a, m, h$-subcapitular setae; or - adoral seta; as - axillary saccule; $I, I I$ - pedotecta I, II, respectively; $1 b, 3 b, 4 a, 4 b$-epimeral setae; dis-discidium; $c p$ - circumpedal carina; $g$, $a g$, an, ad-genital, aggenital, anal and adanal setae, respectively; iad - adanal lyrifissure; $A p$ postanal porose area; $p o$ - preanal organ; $\mathrm{Tr}, \mathrm{Fe}$, $\mathrm{Ge}, \mathrm{Ti}, \mathrm{Ta}$-leg trochanter, femur, genu, tibia, tarsus, respectively; $p a$ - porose area; $\omega, \sigma, \varphi$-leg solenidia; $\varepsilon$ - leg famulus; $v, e v, b v, l, d, f t, t c, i t$, $p, u, a, s, p v, p l$-leg setae.

\section{SYSTEMATICS}

\section{Superfamily Galumnoidea}

Family Galumnidae 


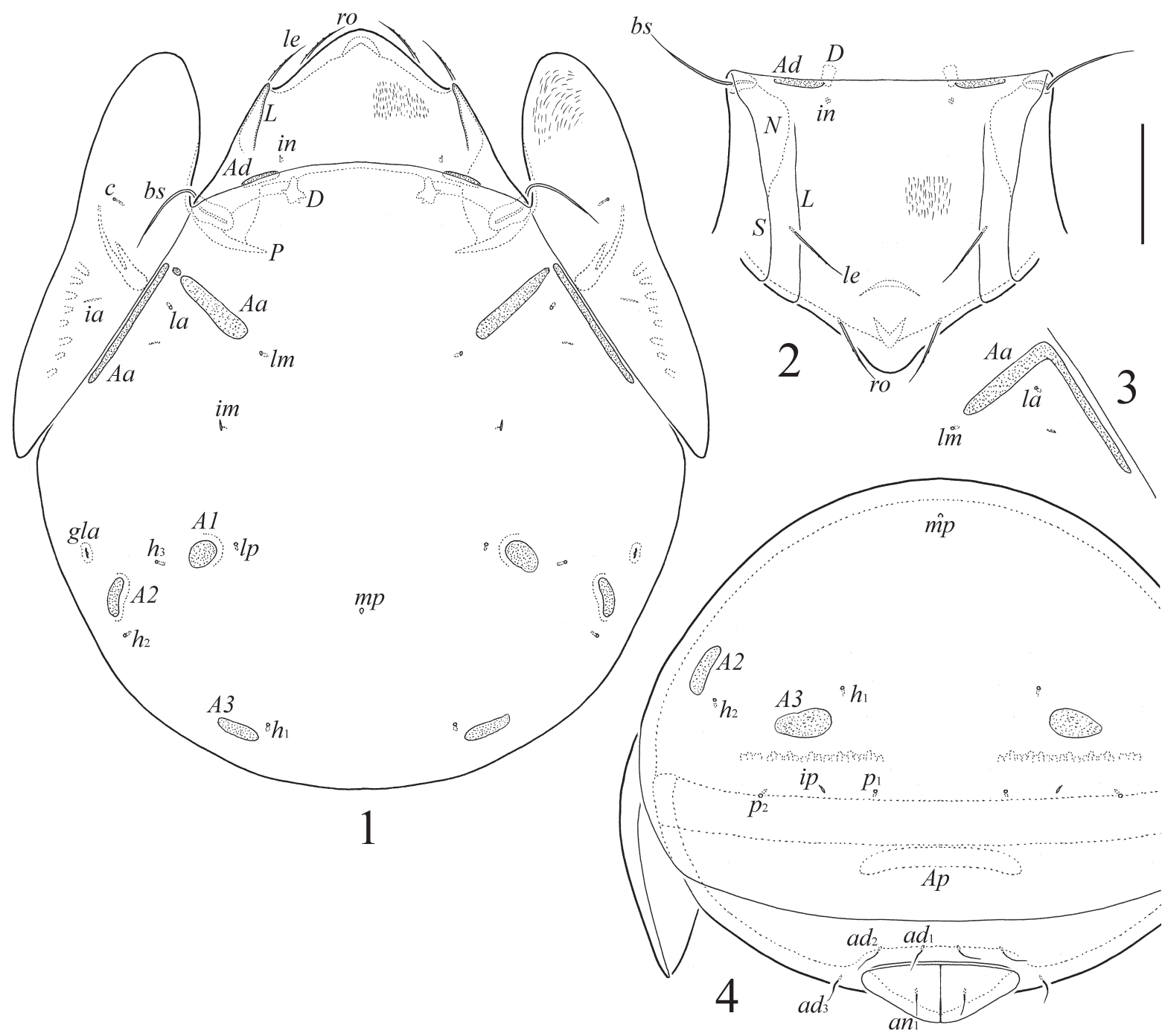

Figs. 1-4. Galumna (Galumna) paracapensis Ermilov sp.n., adult: 1-dorsal view; 2-anterior part of prodorsum, dorsoanterior view; 3 - complete notogastral porose area $A a ; 4$ - posterior view. Scale bar $=200 \mu \mathrm{m}$.

Genus Galumna Heyden, 1826

Subgenus Galumna (Galumna) Heyden, 1826

Type species Notaspis alatus Hermann, 1804

\section{Galumna (Galumna) paracapensis Ermilov, sp.n.}

(Figs. 1-13)

Diagnosis. Body size: 1,195-1,310×1,0121,095. Rostrum rounded. Prodorsum and partially pteromorphs with sculpturing (short ridges). Lamellar and sublamellar lines long, parallel, curving backwards. Rostral, lamellar and bothridial setae of medium size, setiform, ro and le slightly barbed, $b s$ roughened. Interlamellar setae vestigial. Dorsosejugal porose areas, median pore and strongly elongate oval postanal porose area present. Four pairs of notogastral porose areas: Aa boomeranglike, others oval to elongate oval. Epimeral and anogenital setae short, setiform, slightly barbed. Solenidion on leg tibiae IV inserted in anterior part of the segment.

Description. Measurements. Body length: 1,195 (holotype, male), 1,228-1,310 (three paratypes, one male and two females); notogaster width: 1,012 (holotype), 1,029-1,095 (three paratypes). Females larger than males: 1,261-1,310×1,0791,095 vs. $1,195-1,228 \times 1012-1029$.

Integument (Figs. 11, 12). Body color brown. Body surface punctate and partially microgranulate (visible under high magnification: $\times 1,000$ ). Prodorsum and anterior, lateral and posterior parts of pteromorphs with short ridges. Lateral parts of epimeres I and II with rounded and elongated tubercles and partially with short ridges.

Prodorsum (Figs. 1, 2, 7). Rostrum rounded. Lamellar and sublamellar lines long, parallel, curv- 


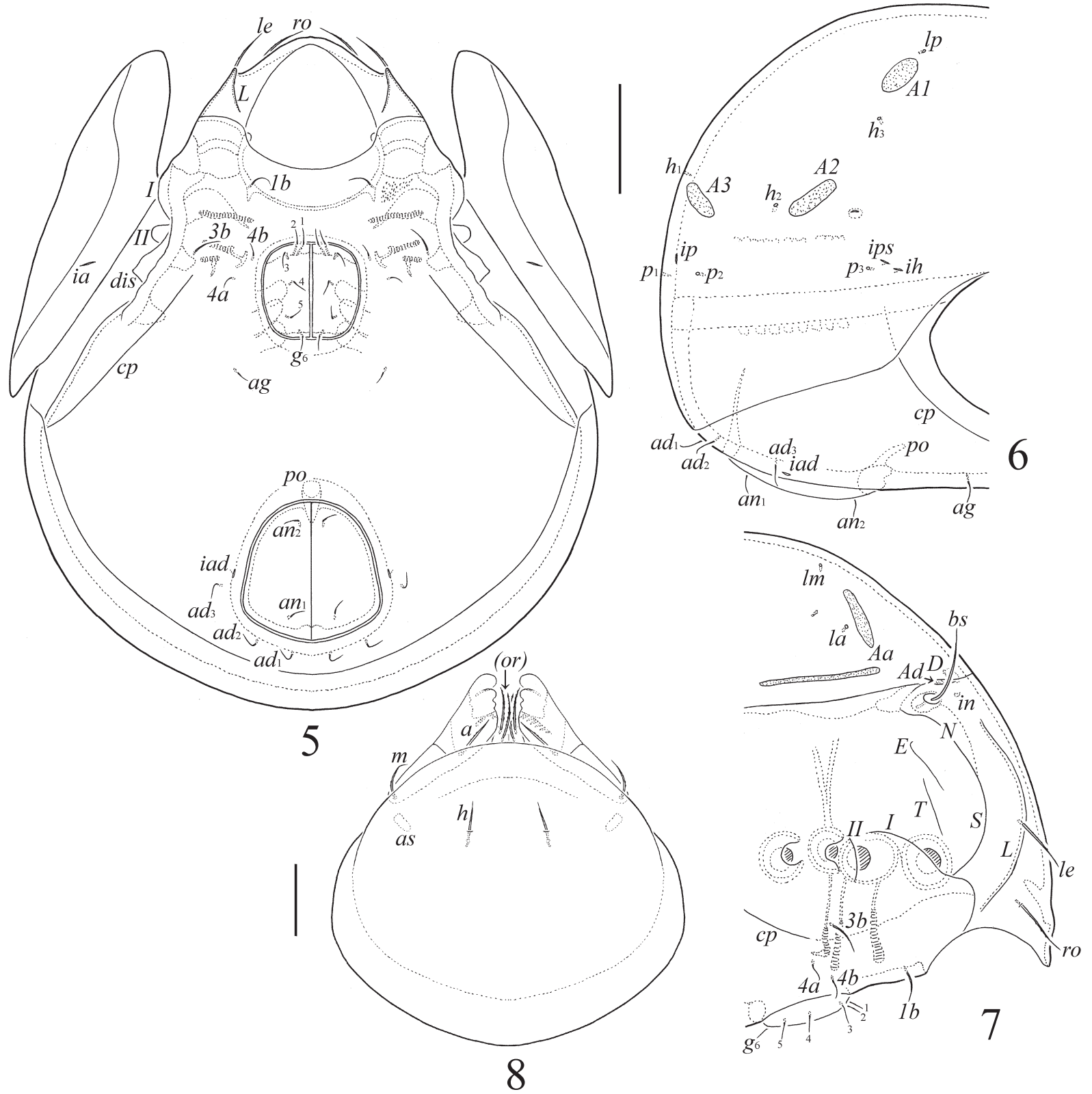

Figs. 5-8. Galumna (Galumna) paracapensis Ermilov sp.n., adult: 5-ventral view (not shown: gnathosoma and legs); 6- posterior part of body, lateral view; 7-anterior part of body, lateral view (not shown: gnathosoma, pteromorph and legs); 8 - subcapitulum, ventral view. Scale bars $=200 \mu \mathrm{m}(5-7), 50 \mu \mathrm{m}(8)$.

ing backwards, $L$ slightly thicker than $S$. Lateral structures $N$ and ridges $E$ and $T$ poorly developed. Rostral and lamellar setae similar in length (106114), setiform, slightly barbed. Interlamellar setae (1) vestigial. Bothridial setae (143-155) setiform, roughened. Exobothridial setae and their alveoli absent. Dorsosejugal porose areas $(65-86 \times 10-12)$ elongate oval, transversely oriented, located posterolateral to interlamellar setae. Dorsophragmata slightly elongated longitudinally.

Notogaster (Figs. 1, 3, 4, 6, 7). Dorsosejugal suture complete, slightly convex medially. With 10 pairs of setal alveoli and four pairs of porose areas:
Aa boomerang-like, sometimes interrupted in angles, medial parts $(180-205 \times 24-32)$ transverse, lateral parts (229-287×12-16) longitudinal, very close to pteromorphal hinges, narrower than medial parts; $A 1(53-90 \times 36-45), A 2(73-110 \times 28-32)$ and $A 3$ $(90-123 \times 24-41)$ oval or elongate oval. Median pore present in both sexes, located between $A 2$. Opisthonotal gland openings and all lyrifissures distinct; gla located anterolateral to $A 2$ and removed from them, im between $A a$ and $A 1$, ip between $p_{1}$ and $p_{2}$, ih and ips located close to each other, anterior to $p_{3}$.

Gnathosoma (Fig. 8). Size of subcapitulum: 270-274×262-266. Subcapitular setae ( $a$ and $m$, 


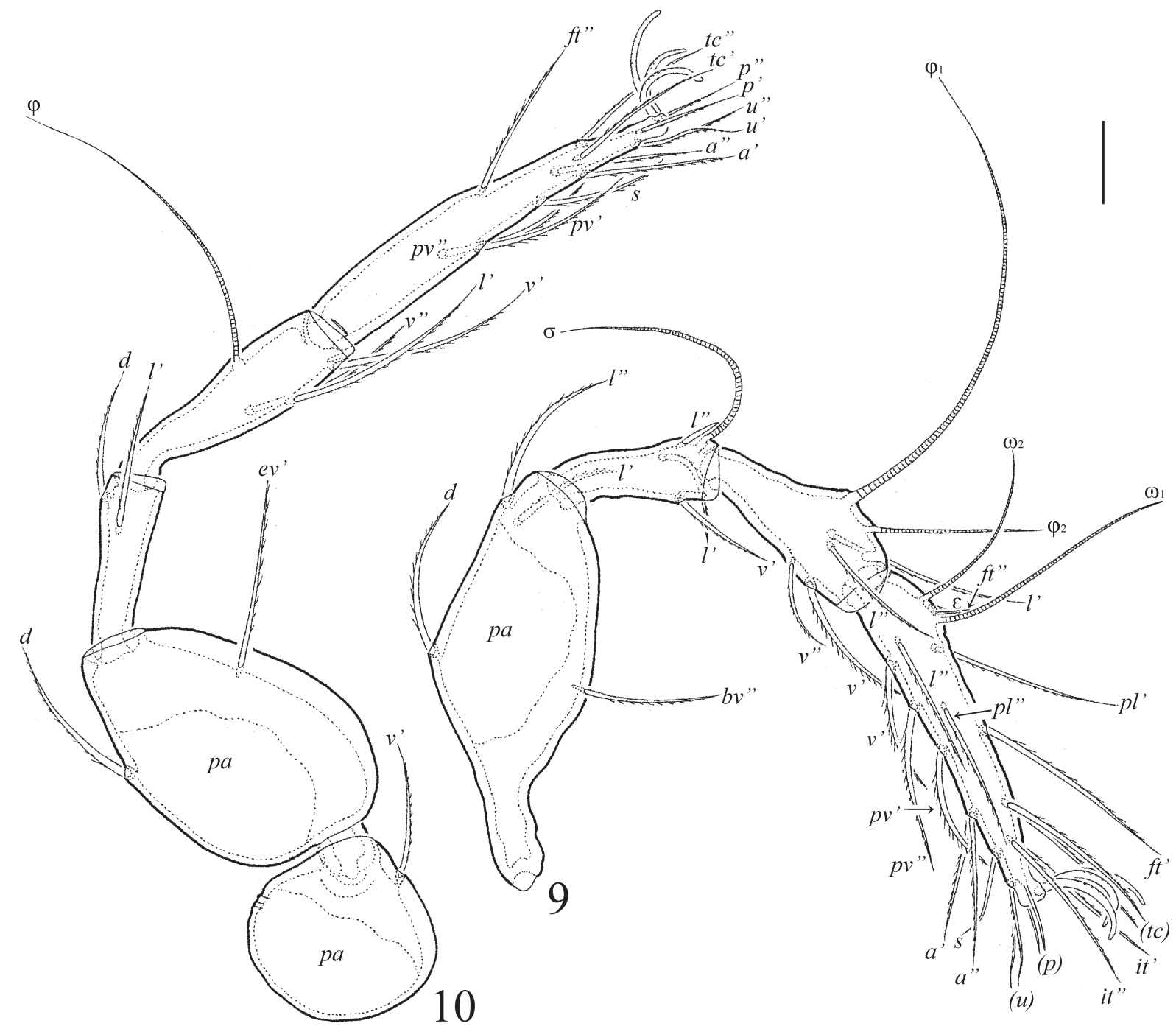

Figs. 9-10. Galumna (Galumna) paracapensis Ermilov sp.n., adult: 9-leg I, without trochanter, right, antiaxial view; 10 - leg IV, left, antiaxial view. Scale bar $=50 \mu \mathrm{m}$.

$36-45 ; h, 32-41)$ setiform, slightly barbed; $a$ thickest. Adoral setae (36-41) setiform, barbed. Palps (184-188) with typical formula $0-2-1-3-9(+\omega)$. Postpalpal setae (12) thorn-like. Length of chelicerae: 314-318. Cheliceral setae (cha, 90-94; chb, 65-69) setiform, barbed. Trägårdh's organ of chelicerae long, elongate triangular.

Epimeral and lateral podosomal regions (Figs. 2, 7). Anterior tectum of epimere I smooth. Epimeral setal formula 1-0-1-2. Epimeral setae setiform, slightly barbed; $I b$ and $3 b$ (65-69) longer than $4 a$ and $4 b(36-41)$. Pedotecta I and II rounded in ventral aspect. Discidia triangular. Circumpedal carinae of medium size, thin, directed to insertions of epimeral setae $3 b$ but not reaching them.

Anogenital region (Figs. 4-7). Six pairs of genital, one pair of aggenital, two pairs of anal and three pairs of adanal setae comparatively similar in length (36-41) setiform, slightly barbed. Anterior edge of genital plates with two setae. Aggenital setae located between genital and anal apertures, closer to the former. Adanal lyrifissures located close and parallel to anal plates. Adanal setae $a d_{1}$ and $a d_{2}$ posterior, $a d_{3}$ lateral to anal plates. Unpaired postanal porose area elongate oval, not shorter than width of two anal plates $(266-287 \times 28-32)$. Ovipositor elongated $(499 \times 131)$, blades $(274)$ longer than length of distal section (beyond middle fold; 225). Each of the three blades with four smooth setae, $\psi_{1} \approx \tau_{1}$ (151) setiform, $\psi_{2} \approx \tau_{\mathrm{a}} \approx \tau_{\mathrm{b}} \approx \tau_{\mathrm{c}}$ (49) thorn-like. Coronal setae (6) spiniform.

Legs (Figs. 9, 10, 13). Claws slightly differ in size and thickness, all barbed on dorsal sides. Porose areas on all femora and on trochanters III, IV poorly visible. Formulas of leg setation and solenidia: I (1-4-3-4-20) [1-2-2], II (1-4-3-4-15) 

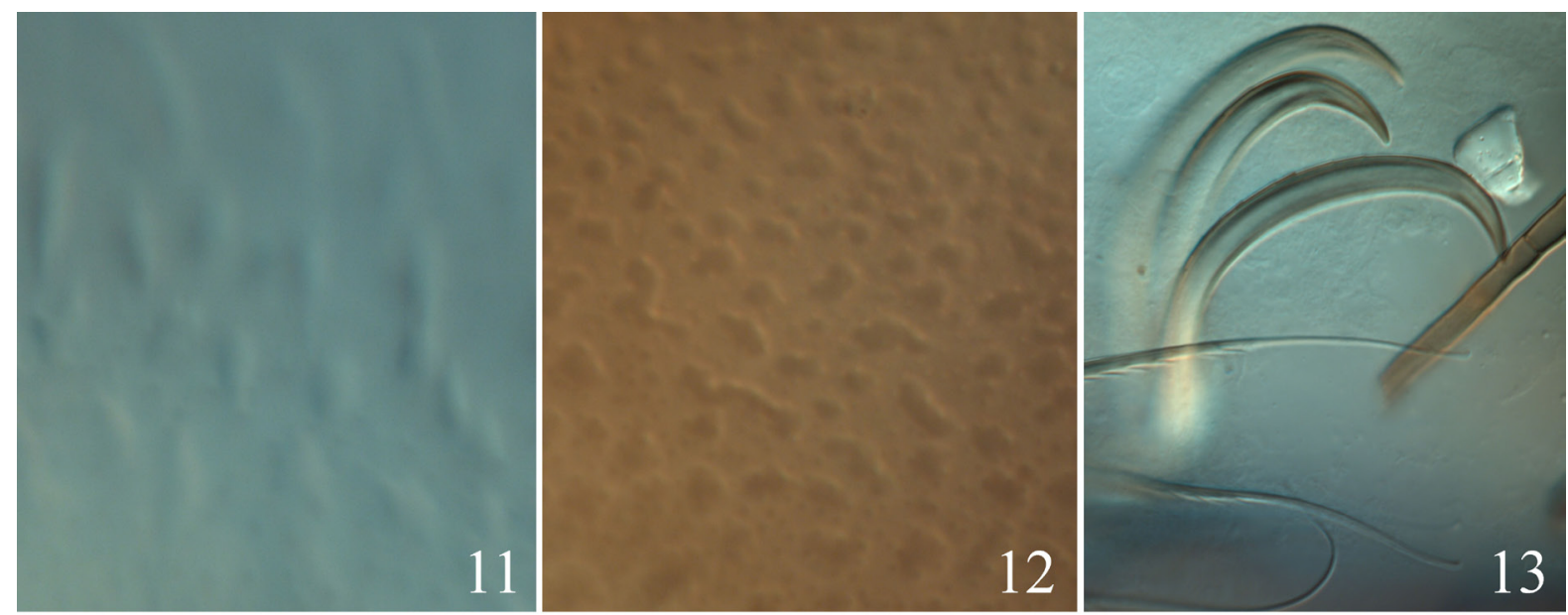

Figs. 11-13. Galumna (Galumna) paracapensis Ermilov sp.n., adult, microscope images: 11-sculpturing on prodorsum; 12 - sculpturing in lateral part of epimere I; 13 — claws of leg III.

[1-1-2], III (1-2-1-3-15) [1-1-0], IV (1-2-2-312) $[0-1-0]$; homologies of setae and solenidia indicated in Table 1. Famulus on tarsi I inserted posteriorly to solenidion $\omega_{1}$. Solenidion on tibiae IV inserted in anterior part of the segment.

Material examined. Holotype (male) and three paratypes (one male and two females): Ethiopia, Bale Mountains, Sanetti Plateau, Afro-Alpica, sparse vegetation, dominated by cushion-shaped shrubs (Helichrysum splendidum, with Festuca richardii, Pentaschistis pictigluma as codominants), $06^{\circ} 48^{\prime}$ 40.7"N, 39 51'07.7"E, 4,050 $\mathrm{m}$ a.s.1., litter and fallen leaves, Berlese's funnels, 16.XI.2014, collected by E. Kuzmicheva.

Type deposition. The holotype is deposited in the collection of the Senckenberg Institute, Görlitz, Germany; three paratypes are deposited in the collection of the Tyumen State University Museum of Zoology, Tyumen, Russia. All in ethanol with a drop of glycerol.

Etymology. The specific name paracapensis refers to the similarity between the new species and Galumna capensis Engelbrecht, 1969.

Remarks. Galumna (Galumna) paracapensis Ermilov sp.n. is morphologically most similar to Galumna (Galumna) capensis Engelbrecht, 1969 from the Ethiopian region (see Engelbrecht 1969) in the presence of dorsosejugal suture, median pore, setiform bothridial setae, four pairs of notogastral porose areas with boomerang-like $A a$ and minute interlamellar setae. The former species differs from the latter in larger body size $(1,195-1,310 \times 1,012$ 1,095 versus $630 \times 504$ ), presence (versus absence) of sculpturing on the prodorsum and on the pteromorphs, strongly elongate (versus oval) postanal porose area and long (versus distinctly shorter) longitudinal parts of porose areas $A a$.

\section{ACKNOWLEDGEMENTS}

The work was performed within the framework of the Joint Russian-Ethiopian Biological Expeditions, financially supported by the Russian Academy of Sciences. We are grateful to Drs. A.A. Darkov and Gezahegn Degefe for supporting the field studies and organizing the laboratory work, as well as to Dr. E. Kuzmicheva for her assistance in the field.

\section{REFERENCES}

Engelbrecht, C.M. 1969. Some South African species of the genus Galumna Von Heyden, 1826 (Acari: Galumnidae). Journal of the Entomological Society of Southern Africa, 32(1): 99-122.

Ermilov, S.G. 2016. Additions to the oribatid mite fauna of Central Ethiopia, with description of a new species of Scheloribates (Bischeloribates) (Acari, Oribatida). Spixiana, 39(1): 75-82.

Ermilov, S. G. 2019. Two new species of Oripodoidea (Acari, Oribatida) from Ethiopia. Zoologicheskii Zhurnal, 98(9): 1037-1047.

Ermilov, S.G. and Klimov, P.B. 2017. Generic revision of the large-winged mite superfamily Galumnoidea (Acari, Oribatida) of the world. Zootaxa, 4357(1): 1-72.

Ermilov, S.G. and Rybalov, L.B. 2018. New faunistic and taxonomic data on oribatid mites (Acari, Oribatida) of Ethiopia. Systematic and Applied Acarology, 23(9): 1827-1837.

Ermilov, S. G. and Rybalov, L.B. 2019. New and interesting oribatid mite taxa (Acari, Oribatida) from the Gambela region (Ethiopia). Systematic and Applied Acarology, 24(5): 905-917. 
Ermilov, S.G., Sidorchuk, E.A. and Rybalov, L.B. Mahunka, S. 1982. Oribatids from the Eastern Part of the 2012. Oribatid mites (Acari: Oribatida) of Ethiopia. Zootaxa, 3208: 27-40. Ethiopian Region (Acari) I. Acta Zoologica Academiae Scientiarum Hungaricae, 28(3-4): 293-336.

Table 1

Leg setation and solenidia of Galumna (Galumna) paracapensis Ermilov sp.n.

\begin{tabular}{|l|l|l|l|l|l|}
\hline Leg & $\boldsymbol{T r}$ & $\boldsymbol{F e}$ & $\boldsymbol{G e}$ & $\boldsymbol{T i}$ & $\boldsymbol{T a}$ \\
\hline I & $v^{\prime}$ & $d,(l), b v^{\prime}$ & $(l), v^{\prime}, \sigma$ & $(l),(v), \varphi_{1}, \varphi_{2}$ & $(f t),(t c),(i t),(p),(u),(a), s,(p v), v^{\prime},(p l), l^{\prime}, \varepsilon, \omega_{1}, \omega_{2}$ \\
\hline II & $v^{\prime}$ & $d,(l), b v^{\prime}$ & $(l), v^{\prime}, \sigma$ & $(l),(v), \varphi$ & $(f t),(t c),(i t),(p),(u),(a), s,(p v), \omega_{1}, \omega_{2}$ \\
\hline III & $v^{\prime}$ & $d, e v^{\prime}$ & $l, \sigma$ & $l^{\prime},(v), \varphi$ & $(f t),(t c),(i t),(p),(u),(a), s,(p v)$ \\
\hline IV & $v^{\prime}$ & $d, e v v^{\prime}$ & $d, l$, & $l,,(v), \varphi$ & $f t^{\prime},(t c),(p),(u),(a), s,(p v)$ \\
\hline
\end{tabular}

Note: Roman letters refer to normal setae, Greek letters-to solenidia (except $\varepsilon=$ famulus), Single prime (') marks setae on anterior and double prime (")—-setae on posterior side of the given leg segment. Parentheses refer to a pair of setae. 